\title{
Chemotherapy-induced Toxic Leukoencephalopathy
} Kemoterapi İlişkili Toksik Lökoensefalopati

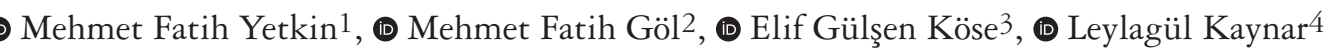 \\ ${ }^{1}$ Erciyes University Faculty of Medicine, Department of Neurology, Kayseri, Turkey \\ 2University of Health Sciences Turkey, Kayseri Training and Research Hospital, Clinic of Neurology, Kayseri, Turkey \\ 3Artvin Public Hospital, Clinic of Neurology, Artvin, Turkey \\ 4Erciyes University Faculty of Medicine, Department of Hematology, Kayseri, Turkey
}

Keywords: Leukoencephalopathy, methotrexate, primary central nervous system lymphoma

Anahtar Kelimeler: Lökoensefalopati, metotreksat, primer merkezi sinir sistemi lenfoması

\section{Dear Editor,}

Leukoencephalopathy is characterized by progressive structural damage in the white matter, mainly due to myelin damage. Metabolic, toxic and infectious agents may cause leukoencephalopathy. Several chemotherapeutic agents, especially methotrexate and 5-fluorouracil (5-FU), have been shown to be associated with leukoencephalopathy.

Primary central nervous system (CNS) lymphoma (PCNSL) is a rare malignancy frequently treated with methotrexate-based chemotherapy regimens. The chemotherapy regimens used in the treatment of PCNSL, especially containing methotrexate and 5-FU, are important causes of leukoencephalopathy characterized by cognitive destruction, gait abnormalities, and urinary incontinence. In this study, we present a chemotherapy-induced leukoencephalopathy case that emerged after diffuse large B cell lymphoma treatment.

A 54-year-old female patient was admitted with symptoms of memory impairment, weakness in the left side of the body, and involuntary contractions. The diagnosis of diffuse large B-cell lymphoma was made with brain imaging (Figure 1) followed by brain biopsy. The patient underwent a cure of methotrexate, cytarabine, thiotepa and rituximab (MATRix) regimen followed by autologous bone marrow transplantation, and subsequently a second cure MATRix regimen. With this treatment, neurologic examination and neuroimaging findings of lymphoma (CNS) showed significant improvement (Figure 2).

However, in the sixth month of chemotherapy, following the third cure of MATRix regimen, she developed symptoms of gait difficulty, memory impairment, inappropriate laughing and crying, bradykinesia, and tremor in the hands.

Follow-up magnetic resonance imaging (MRI) revealed bilateral periventricular white matter hyperintensity on T2 and fluid-attenuated inversion recovery (FLAIR) sequences and brain volume loss, which was not observed in previous MRI examinations (Figure 3), and spinal MRI showed no additional pathology. On neurologic examination, the patient was apathetic and orientation to place and time was lost. Cranial nerve examination was normal and there were no signs of meningeal irritation. Deep tendon reflexes were generalized hypoactive and no pathologic reflex was detected. There was mild rigidity in the upper extremity with postural, kinetic, and resting tremor. Cerebrospinal fluid direct examination, biochemistry, culture, cytology, and flow cytometry were normal. Also, the patient was checked for John Cunningham virus (JCV) antibody status, and no antibodies against JCV were detected. Neuropsychiatric evaluation revealed impaired executive functions and the Mini Mental Status Test score was 16/30.

In spite of the improvement in the lymphoma involvement in the CNS after chemotherapy, worsening of the neurologic examination findings, signal increase in white matter, and and brain volume loss mainly affecting the white matter in the

Address for Correspondence/Yazışma Adresi: Mehmet Fatih Yetkin MD, Erciyes University Faculty of Medicine, Department of Neurology, Kayseri, Turkey Phone: +90542820 3060 E-mail: drfatihmehmet@gmail.com ORCID: orcid.org/0000-0002-2541-7107

Received/Geliş Tarihi: 18.04.2019 Accepted/Kabul Tarihi: 11.11.2019

${ }^{\circ}$ Copyright 2020 by Turkish Neurological Society

Turkish Journal of Neurology published by Galenos Publishing House. 


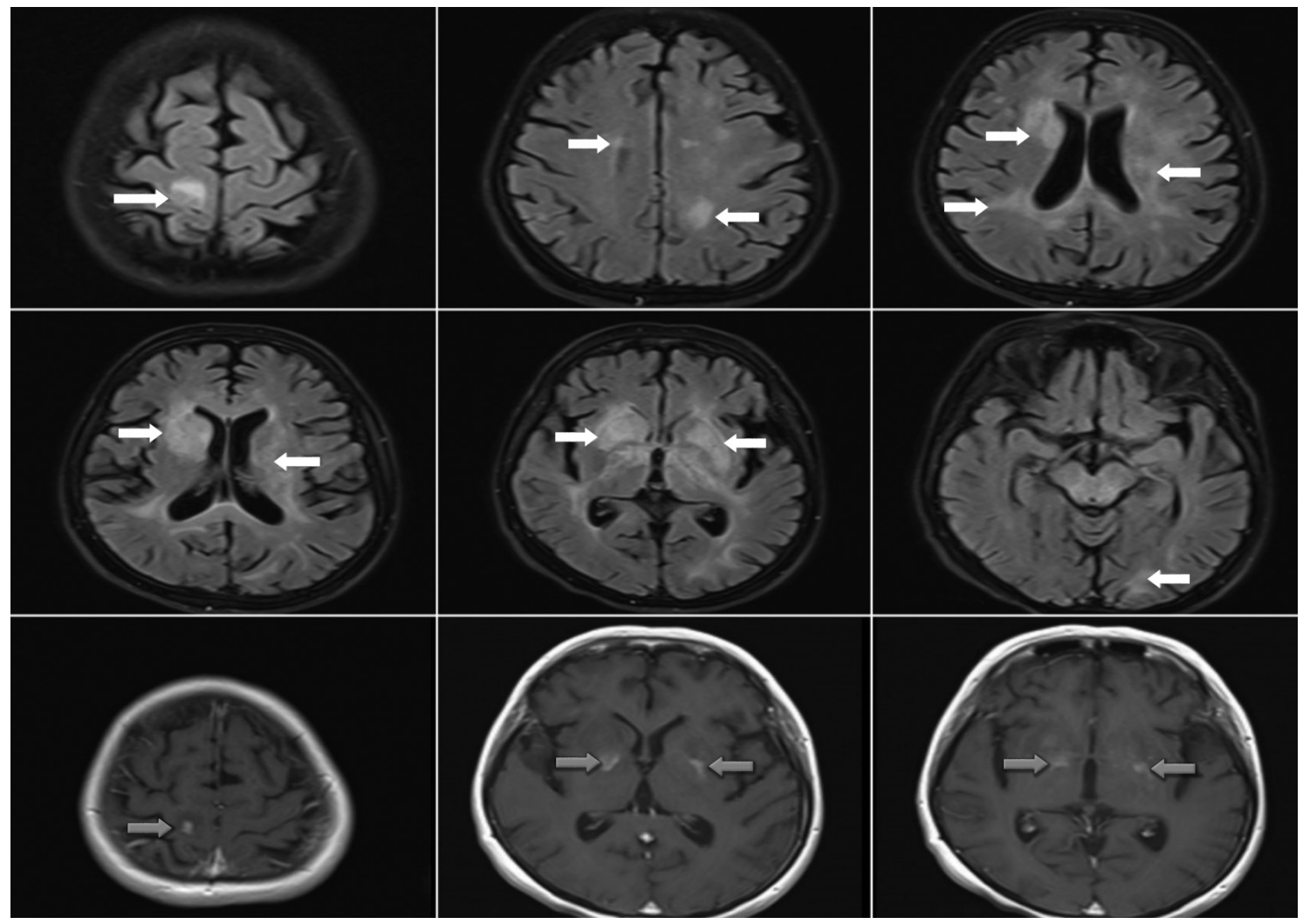

Figure 1. Pre-treatment magnetic resonance imaging revealed diffuse hyperintense lesions in fluid-attenuated inversion recovery sequences (white arrows) with contrast enhancement (gray arrows) consistent with diffuse large B-cell lymphoma involvement

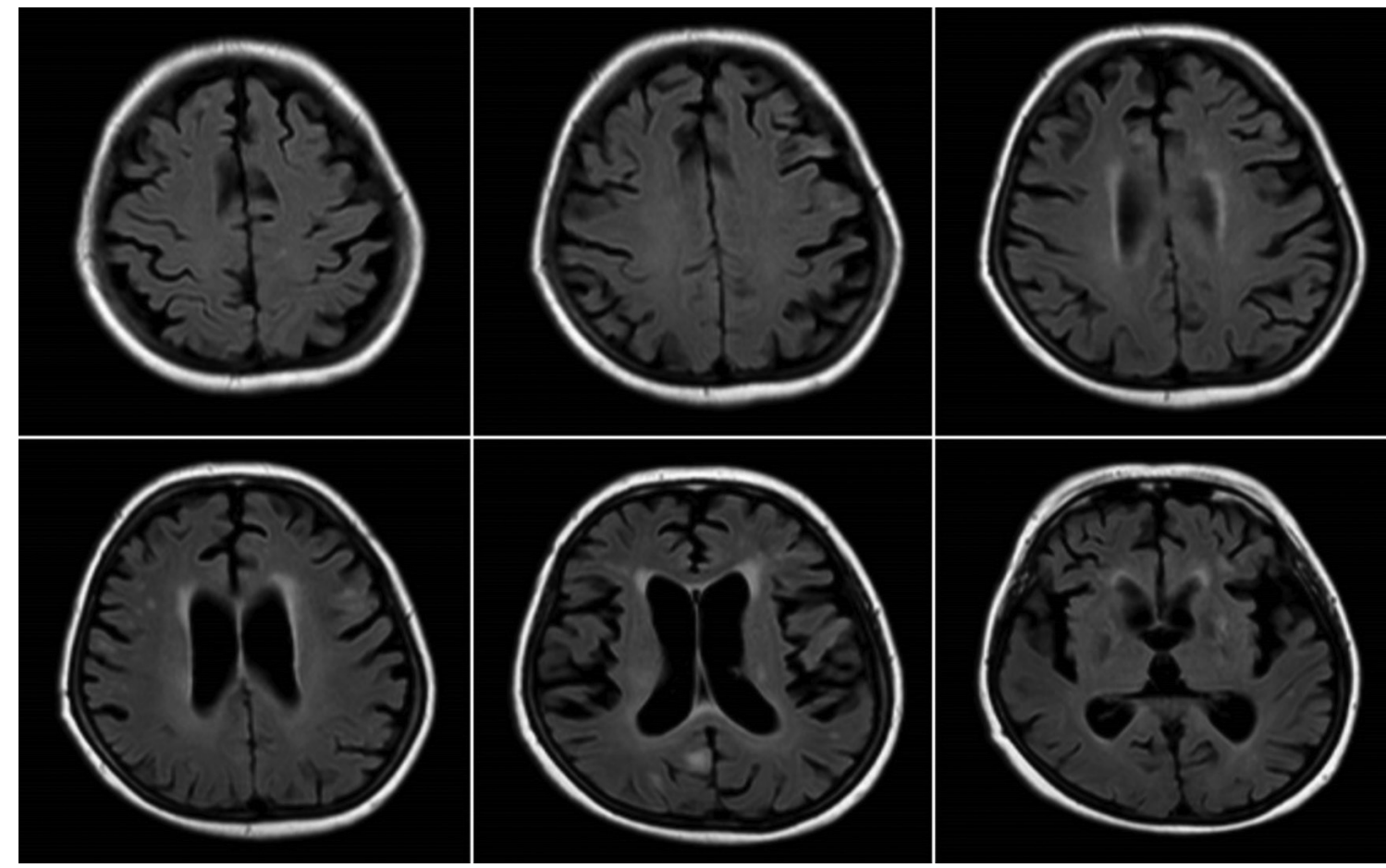

Figure 2. After one cure MATRix regimen with autologous stem cell transplantation significant improvement was observed in fluid-attenuated inversion recovery images

MATRix: Methotrexate cytarabine thiotepa and rituximab 

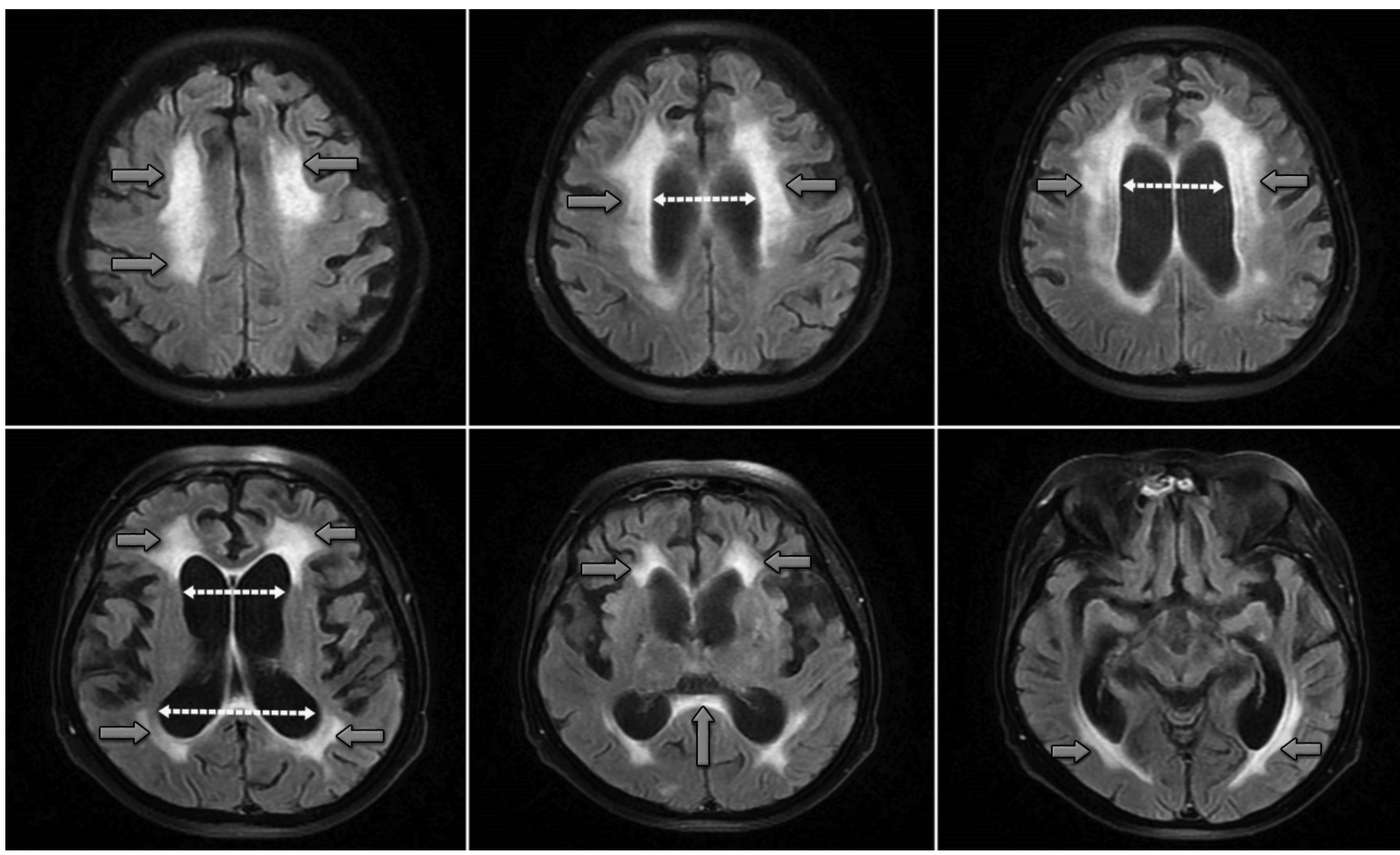

Figure 3. Fluid-attenuated inversion recovery images acquired after the third course of the MATRix regimen show marked hyperintensity (gray arrows) in the bilateral periventricular and deep white matter, and significant white matter loss in the white matter and secondary ventricular dilatation (white arrows)

MATRix: Methotrexate cytarabine thiotepa and rituximab

absence of other white matter disorders, led to a diagnosis of leukoencephalopathy secondary to chemotherapy. L-dopa 375 $\mathrm{mg}$ /day for extrapyramidal system findings and quetiapine 25 $\mathrm{mg} /$ day for affective disorder were recommended. Although the chemotherapy regimen was terminated, the patient's neurologic examination findings did not improve.

Leukoencephalopathy is a condition characterized by progressive structural damage in the cerebral white matter, resulting from myelin damage. Metabolic causes, infections, radiation exposure, toxic agents are among the leading causes of leukoencephalopathy. Toxic leukoencephalopathy caused by chemotherapeutic agents is an important issue because the damage can be reversed if the exposure is discontinued before the onset of irreversible injury (1). Chemotherapeutic agents known to cause neurotoxicity include methotrexate, 5-FU, vincristine, cyclosporine, ifosfamide, fludarabine, and cisplatin (2). Before hyperintensity occurs in FLAIR images, in the acute phase, diffusion-weighted images may show focal or diffuse diffusion restriction, as well as hypointensity regions in apparent diffusion coefficient sequences. Improvement may be observed in this period when the drug is discontinued. However, if abnormalities on conventional MRI develop, such as T2 and FLAIR hyperintensities, a longer time for recovery is needed (3). Unfortunately, our patient did not improve despite discontinuation of chemotherapy.

Acute toxic leukoencephalopathy should be considered in the differential diagnosis of a patient with recently emerging neurologic deficits and white matter abnormalities on MRI, in the presence of a known toxin exposure.

In patients receiving chemotherapy, especially chemotherapy regimens containing methotrexate, a strong clinical suspicion for acute toxic leukoencephalopathy should arise in the presence of new neurologic deficits. Early termination of chemotherapy regimen may reverse neurologic deficits.

\section{Ethics}

Informed Consent: Informed consent was given by the patient.

Peer-review: Externally peer-reviewed.

\section{Authorship Contributions}

Surgical and Medical Practices: M.F.Y., M.F.G., E.G.K., L.K., Concept: M.F.Y., M.F.G., E.G.K., L.K., Design: M.F.Y., M.F.G., E.G.K., L.K., Data Collection or Processing: M.F.Y., M.F.G., E.G.K., L.K., Analysis or Interpretation: M.F.Y., M.F.G., E.G.K., L.K., Literature Search: M.F.Y., M.F.G., E.G.K., L.K., Writing: M.F.Y., M.F.G., E.G.K., L.K. 
Conflict of Interest: No conflict of interest was declared by the authors.

Financial Disclosure: The authors declared that this study received no financial support.

\section{References}

1. Sindhwani G, Arora M, Thakker VD, Jain A. MRI in chemotherapy induced leukoencephalopathy: report of two cases and Radiologist's perspective. J Clin Diagn Res 2017;11:TD08-TD09.
2. McKinney AM, Kieffer SA, Paylor RT, SantaCruz KS, Kendi A, Lucato L. Acute toxic leukoencephalopathy: potential for reversibility clinically and on MRI with diffusion-weighted and FLAIR imaging. AJR Am J Roentgenol 2009;193:192-206.

3. Salkade PR, Lim TA. Methotrexate-induced acute toxic leukoencephalopathy. J Cancer Res Ther 2012;8:292-296. 